\title{
Produção de vodca a partir de batata (Solanum tuberosum $L$.) cultivar ágata, utilizando Saccharomyces cerevisiae
}

\author{
A. G. T. MENEZES ${ }^{1 *}$, E. G. T. MENEZES ${ }^{1}$, J. G. L. F. ALVES ${ }^{1}$ \\ ${ }^{1}$ Universidade Federal de Lavras, Departamento de Ciência dos Alimentos \\ *e-mail para contato: alinegtm@msn.com, jlembi@dca.ufla.br
}

\begin{abstract}
RESUMO - O trabalho teve como objetivo avaliar a utilização de batata cultivar ágata como substrato para produção de vodca utilizando fermento de panificação. Foram testadas duas concentrações de sólidos solúveis no meio de fermentação, um contendo apenas meio hidrolisado de batata $\left(11^{\circ}\right.$ Brix $)$ e outro contendo meio hidrolisado de batata acrescido de sacarose $\left(17^{\circ}\right.$ Brix). Foram avaliadas quanto ao rendimento fermentativo e à produção de etanol. Os melhores resultados foram obtidos com o tratamento 2, com maior conversão de substrato em produto $(0,47 \mathrm{~g}$ etanol/gART), maior rendimento $(91,4 \%)$ e maior teor alcoólico $(6,05 \% \mathrm{v} / \mathrm{v})$. Foi feita nova fermentação, e em seguida, foram realizadas duas destilações consecutivas, uma em alambique de cobre e outra em coluna de vidro com recheio de silicone. $O$ destilado foi filtrado em carvão ativado e foram realizadas análises de compostos secundários, sendo seus valores comparados com o padrão de identidade e qualidade da vodca estabelecido pela legislação brasileira. Pode-se perceber que o teor alcoólico $(39,7 \%$ v/v) se enquadrou na faixa estipulada pela legislação, assim como os teores de cobre e furfural, que não foram detectados. Porém, a soma dos compostos secundários foi superior à exigida (máximo $50 \mathrm{mg} / 100 \mathrm{~mL}$ álcool anidro) assim como teor de metanol (máximo de $20 \mathrm{mg} / 100 \mathrm{~mL}$ álcool anidro), que poderiam ser corrigidos com uso de outros tipos de carvão ativado ou alterações na destilação.
\end{abstract}

\section{INTRODUÇÃO}

Dentre as matérias primas açucaradas, existem aquelas que são denominadas diretamente fermentescíveis e as não diretamente fermentescíveis. As primeiras são as que possuem monossacarídeos, como sucos de frutas. As não diretamente fermentescíveis são aquelas que contêm dissacarídeos, como por exemplo, a sacarose presente na cana de açúcar, que fermenta após hidrólise, que ocorre naturalmente pela ação da enzima invertase produzida pelo agente de fermentação, no caso de Saccharomyces cerevisiae. Existem, também, materiais que não são fermentescíveis pela levedura, como, por exemplo, materiais lignocelulósicos e amiláceas que necessitam de tratamentos antes de serem disponibilizados para fermentação (LIMA et al., 2001).

Além da formação de álcool etílico e dióxido de carbono, ocorre, também, a formação de pequenas quantidades de outros componentes, que recebem a denominação de compostos secundários da fermentação alcoólica, tais como ácidos carboxílicos, ésteres, aldeídos e álcoois superiores.Também podem ser encontrados os chamados contaminantes de bebidas alcoólicas, 


\section{9 a 22 de outubro de 2014 \\ Florianópolis/SC}

que podem ser de natureza orgânica (carbamato de etila, metanol, acroleína, entre outros) ou inorgânica (cobre, chumbo, arsênio, entre outros) (CARDOSO, 2013).

A vodca é uma bebida que pode ser obtida de matéria prima amilácea como a batata. Possui graduação alcoólica de $36 \%$ a $54 \%$ em volume a $20{ }^{\circ} \mathrm{C}$, e é obtida de álcool etílico potável de origem agrícola ou do destilado alcoólico simples de origem agrícola retificados, seguidos ou não de filtração por meio de carvão. Estes procedimentos reduzem as características organolépticas originais da matéria prima utilizada. Ela pode ser adicionada de aromatizantes para dar ao produto características organolépticas especiais (SIŘÍŠŤOVÁ et al., 2012).

O passo tecnológico mais importante na produção da vodca clássica é assumido como sendo a sua purificação com carvão ativado. Processos mais simples estão baseados na adsorção de substâncias em carvão ativado envolvendo a agitação de certa quantidade de carvão em uma solução de etanol. O processo é finalizado filtrando as partículas sólidas (SIŘÍŠŤOVÁ et al., 2012). Outra possibilidade é a filtração da solução de etanol por uma grande quantidade de carvão ativado, embalado em uma coluna ou em várias colunas em série. A solução flui pelas colunas assegurando um contato suficiente da fase sólida e líquida (KOVALIÓV et al., 2007 apud SIŘÍŠŤTVÁ et al., 2012).

Objetivou-se neste trabalho analisar diferentes isolados de $S$. cerevisiae na produção de vodca a partir de batata e avaliar a estratégia de dupla destilação seguida de filtração com carvão ativado, para que o produto final atenda às exigências da legislação brasileira quanto ao teor dos compostos secundários.

\section{MATERIAIS E MÉTODOS}

\subsection{Substrato e enzimas}

Batata ágata foi adquirida do comercio local de Lavras, Minas Gerais. Foi realizada sua lavagem em água corrente, descascada manualmente e triturada em liquidificador industrial (Poli modelo LS-06, Brusque/Brasil). Após a trituração, o lote de material foi homogeneizado e armazenado em sacos plásticos a $-18{ }^{\circ} \mathrm{C}$ em freezer. As enzimas utilizadas foram $\alpha$-amilase (Termamyl 2X) e a enzima amiloglicosidase (AMG 300L) fornecidas pela empresa Romerlabs.

\subsection{Hidrólise enzimática}

Para hidrólise do amido, foi utilizado uma proporção em base seca de polpa de 0,1502 g/g (polpa/água). Para primeira etapa da hidrólise, o $\mathrm{pH}$ foi ajustado para faixa ótima da enzima $\alpha$ amilase, entre 6,0 e 6,5 utilizando $\mathrm{NaOH} 2 \mathrm{~N}$. A mistura foi mantida sob agitação em banhomaria a $90^{\circ} \mathrm{C}$ por $1 \mathrm{~h}$ para a completa gelatinização. Após esse período de tempo, a primeira enzima $\alpha$-amilase (Termamyl $2 \mathrm{X}$ ) foi adicionada na proporção de $7,5 \mathrm{~mL} / \mathrm{Kg}$ de matéria seca e foi mantida sob essa temperatura por $2 \mathrm{~h}$. Na segunda etapa, o $\mathrm{pH}$ foi ajustado para condições ótimas da enzima amiloglicosidase (AMG 300L), entre 4,0 e 4,5 adicionando $\mathrm{HCl} 2 \mathrm{~N}$. Resfriou- 
se o líquido para $60^{\circ} \mathrm{C}$ e adicionou-se a enzima na proporção de $6,5 \mathrm{~mL} / \mathrm{Kg}$ de matéria seca e esta foi mantida por mais 11,04 horas, sob agitação, totalizando 14,04 horas de hidrólise. Ao final do processo o hidrolisado foi filtrado manualmente em tecido organza.

\subsection{Fermentação}

\subsubsection{Preparo do inóculo}

Com o propósito de reativar as células de leveduras e atingir valores iguais a $10^{8}$ células viáveis/mL, foi realizada a reativação, utilizando utilizados $10 \mathrm{~g}$ de fermento para $50 \mathrm{~mL}$ de água. Antes da adição do inóculo ao mosto a ser fermentado, foram feitas contagens e testes de viabilidade das leveduras.

\subsubsection{Condução do processo fermentativo}

Erlenmeyers com $500 \mathrm{~mL}$ de hidrolisado foram autoclavados a $121^{\circ} \mathrm{C}$ e $1,1 \mathrm{Kgf} / \mathrm{cm}^{2}$ por 15 min. Foram realizados dois tratamentos, tratamento 1 (T1), somente com polpa de batata hidrolisada a $11^{\circ}$ Brix e o tratamento 2 (T2), onde os sólidos solúveis da polpa hidrolisada foram ajustados para $17^{\circ}$ Brix com sacarose, sendo os tratamentos realizados em triplicata. Os frascos foram inoculados com $10 \%$ do inóculo e mantidos à temperatura de $30{ }^{\circ} \mathrm{C}$ em incubadora BOD sem agitação. Para o estudo cinético, foram retiradas amostras do mosto fermentado nos tempos de $0,2,4,6,8,10,12,24$ e 48h. Foram realizadas análises de açúcares redutores e redutores totais. A cada 4 horas, amostras foram retiradas para análise de teor alcoólico.

\subsection{Análises físico-químicas}

\subsubsection{Açúcares redutores (AR) e açúcares redutores totais (ART)}

As concentrações de AR e ART foram determinadas, de acordo com o método DNS (ácido 3,5 dinitrossalicílico), proposto por Miller (1959). As leituras da absorbância das amostras hidrolisadas foram efetuadas em espectrofotômetro modelo Femto 700s, a $540 \mathrm{~nm}$. Para zerar o espectrofotômetro, preparou-se um branco em que o volume da amostra foi substituído por água purificada. Para o cálculo de AR e ART, foram feitas curvas de calibração com glicose e sacarose, respectivamente.

\subsubsection{Teor alcoólico}

Para análise do teor de etanol, foi feita a destilação das amostras, em microdestilador e foi, então, realizada a medição da densidade do destilado utilizando-se picnômetro. A graduação 
alcoólica do destilado a $20^{\circ} \mathrm{C}$ foi obtida utilizando a tabela de conversão de densidade em porcentagem de álcool em volume. O resultado foi expresso em $\%$ de álcool em volume (INSTITUTO ADOLFO LUTZ, 2008).

\subsubsection{Conversão do substrato em etanol ( $Y p / s)$, eficiência fermentativa $\left(E_{f}\right)$ e produtividade em etanol}

O fator de conversão do substrato em etanol ou rendimento foi calculado em gramas de etanol por gramas de glicose totais consumidos (Equação 1).

$$
Y p / s=(P f-P i) /(S i-S f)
$$

onde Pf: concentração de etanol no final da fermentação (g etanol/L); Pi: concentração de etanol no início da fermentação (g etanol/L); Si: concentração de açúcares redutores (tratamento 1) ou totais (tratamento 2) no início da fermentação (g AR/L); Sf: concentração de açúcares redutores (tratamento 1) ou totais (tratamento 2) no final da fermentação (g AR/L ou gART/L).

A eficiência fermentativa é a fração do açúcar metabolizado que se converteu em etanol. Foi calculada pela relação entre o rendimento do etanol observado no processo e o rendimento teórico (equação 2).

$$
E_{f}=\left(\frac{Y p / s}{0,511}\right) \times 100
$$

A produtividade em etanol $\left(\mathrm{Q}_{\mathrm{p}}\right)$ expressa o teor produzido de etanol em certo intervalo de tempo, quantificada em gramas de etanol por litro de meio fermentado por hora $\left(\mathrm{g} \mathrm{L}^{-1} \mathrm{~h}^{-1}\right)$. Foi calculada empregando-se a Equação 3:

$$
Q_{p}=P / t_{f}
$$

onde P: concentração de etanol no final da fermentação ( $\mathrm{g}$ etanol/L); $\mathrm{t}_{\mathrm{f}}$ : tempo final da fermentação (horas).

\subsection{Destilação}

Utilizando as melhores condições obtidas de fermentação (tratamento 2), a amostra foi clarificada por centrifugação e destilada em alambique de cobre equipado com termômetro e com sistema de aquecimento a gás com capacidade de 15 litros. O destilado obtido no alambique foi, então, retificado em coluna de vidro com recheio de anéis de silicone. Foi colocado $1 \mathrm{~L}$ do destilado em um balão de 2 litros de fundo redondo, $10 \%$ do destilado inicial foi retirado, que correspondia à fração cabeça, e a fração coração correspondendo a $80 \%$ do volume destilado restante. O teor alcoólico final foi ajustado com água purificada e a medida foi realizada com 
alcoômetro de Gay-Lussac. O destilado foi armazenado em garrafas de vidro tampadas e mantidas em temperatura ambiente ate a etapa de filtração.

\subsection{Filtração}

Foi colocado volume de $500 \mathrm{~mL}$ da amostra produzida em béquer, onde foi adicionado carvão ativado em pó comercial (Chemco, lote 10698) na concentração de 26 g.L ${ }^{-1}$. A mistura foi submetida à agitação $(150 \mathrm{rpm})$, à temperatura ambiente por 60 minutos, semelhante ao sugerido por Lima et al. (2006), para filtração de cachaça. Após o tempo, foi feita a filtração, a vácuo, com papel de filtro para eliminação do carvão. A amostra foi acondicionada em garrafa de vidro com tampa e submetida às análises de cobre, acidez volátil, ésteres, dosagem de álcoois superiores, aldeídos, grau alcoólico, furfural e metanol, realizadas no Laboratório de Análises FísicoQuímicas de aguardente do Departamento de Química da UFLA.

\subsection{Compostos secundários}

A determinação dos compostos secundários da vodca foi realizada no Laboratório de Análises Físico-Químicas de aguardente do Departamento de Química da UFLA, seguindo as especificações estabelecidas pelo Decreto 2314 de 04/09/1997, artigo 91 (MAPA).

\section{RESULTADOS E DISCUSSÕES}

\subsection{Açúcares redutores (AR) e açúcares redutores totais (ART)}

Os gráficos das cinéticas de consumo de açúcares redutores e redutores totais durante a fermentação em meio hidrolisado com $11^{\circ}$ Brix (T1) e no meio com hidrolisado acrescido de sacarose com $17^{\circ}$ Brix (T2) podem ser observados nas Figuras 1 e 2.

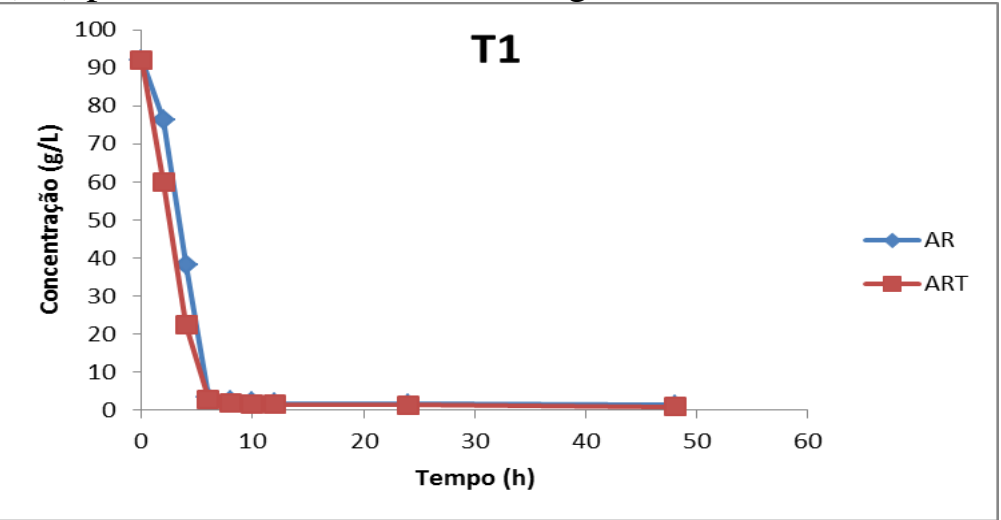

Figura 1 - Cinética do consumo de AR e ART para o tratamento 1 (T1). 
Como se pode notar, no tratamento 1, a quantidade de açúcares redutores (Figura 1) e redutores totais (Figura 2) diminuíram ao longo da fermentação. A fermentação teve início com $92 \pm 7 \mathrm{~g} / \mathrm{Le}$ 92,0 $\pm 0,3 \mathrm{~g} / \mathrm{L}$ para AR e ART, respectivamente, passando para 1,3 $\pm 0,1 \mathrm{~g} \mathrm{AR/L} \mathrm{e}$ $1,83 \pm 0,05 \mathrm{~g}$ A ART/L ao final de 8 horas de fermentação.

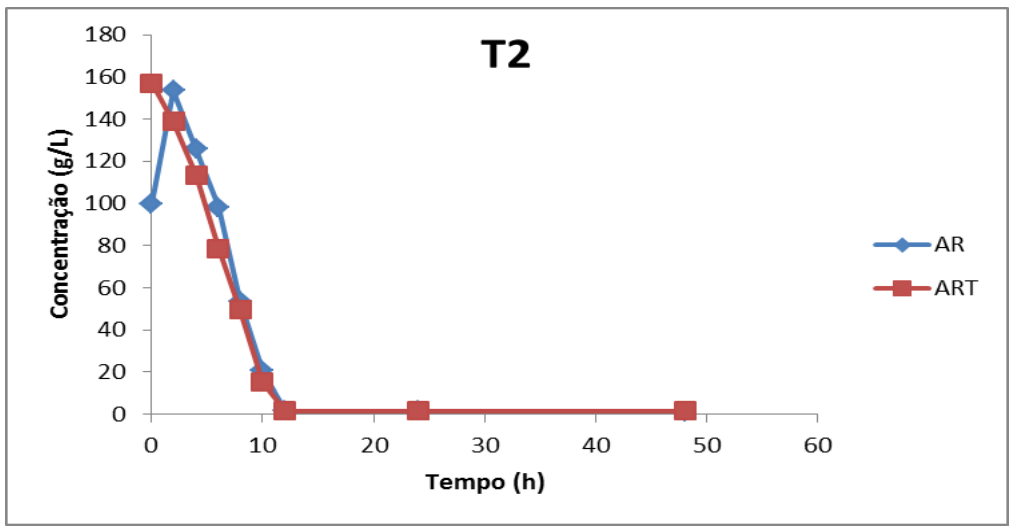

Figura 2 - Cinética do consumo de AR e ART para o tratamento 2 (T2).

Para o tratamento 2, a fermentação teve início com 100,0 gAR/L e 157,0 g ART/L, obtendo-se, ao final da fermentação, 1,2 g AR/L e 1,6 g ART/L, em 12 horas. Nas primeiras 2h, houve um aumento na concentração de açúcares redutores pela quebra da sacarose pela ação das leveduras. Após esse período, pode-se observar que ocorreu a redução das concentrações dos açúcares redutores, em virtude da ação das leveduras, convertendo os açúcares redutores em etanol, um dos principais produtos da fermentação alcoólica (SILVA et al., 2003).

\subsection{Teor alcoólico}

Os resultados de teor alcoólico no meio de fermentação, para os tratamentos 1 e 2, estão apresentados na Figura 3. O teor alcoólico produzido pelo tratamento 1 foi de 4,35\% v/v. Já para o tratamento 2, ao final da fermentação foi produzido $9,2 \% \mathrm{v} / \mathrm{v}$. Pode-se notar que houve diferença na cinética de produção de etanol entre os tratamentos 1 e 2 e o tratamento 2 produziu, praticamente, o dobro de etanol que o tratamento 1.

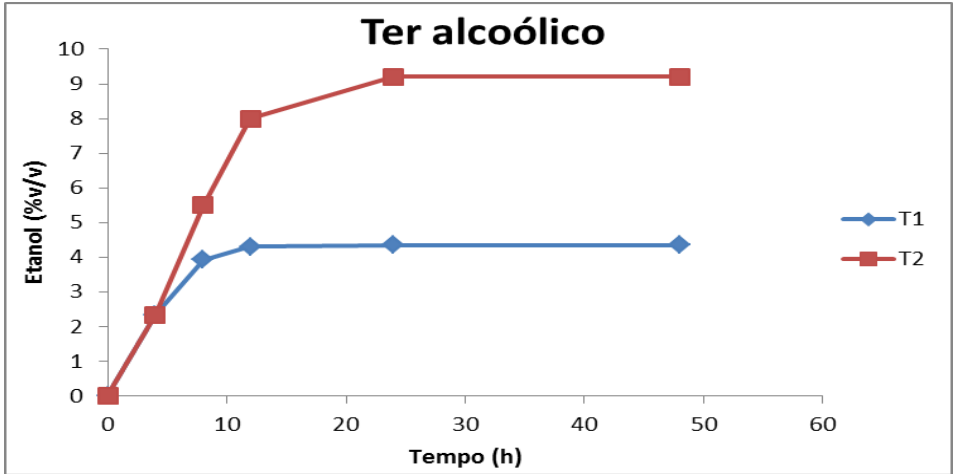

Figura 3 - Evolução do teor alcoólico ao longo da fermentação (T1 e T2). 


\subsection{Conversão do substrato em etanol $(Y p / s)$, eficiência fermentativa $\left(E_{f}\right)$ e produtividade em etanol}

Os valores médios e os desvios padrões dos fatores de conversão em relação à produção de etanol $(\mathrm{Yp} / \mathrm{s})$, à eficiência fermentativa $(\mathrm{Ef})$ e à produtividade em etanol $(\mathrm{Qp})$ encontra-se na Tabela 1, para os tratamentos 1 e 2 . Mediante os resultados pode-se notar que, ao adicionar sacarose ao meio de fermentação, ocorreu aumento significativo para todos os parâmetros.

Tabela 1 Resultados médios para fator de conversão em etanol, eficiência fermentativa e produtividade em etanol para os 2 tratamentos.

\begin{tabular}{cccc}
\hline Tratamento & $\begin{array}{c}\text { Yp/s } \\
(\mathbf{g} \text { etanol/gAR) }\end{array}$ & $\begin{array}{c}\text { Eficiência } \\
\text { fermentativa } \\
(\boldsymbol{\%})\end{array}$ & $\begin{array}{c}\text { Produtividade } \\
(\mathbf{g} / \mathbf{L} . \mathbf{h})\end{array}$ \\
\hline 1 & $0,37 \pm 0,03^{\mathrm{a}}$ & $73,26 \pm 5,27^{\mathrm{a}}$ & $4,23 \pm 0,02^{\mathrm{a}}$ \\
2 & $0,47 \pm 0,01^{\mathrm{b}}$ & $89,39 \pm 1,08^{\mathrm{b}}$ & $5,92 \pm 0,1^{\mathrm{b}}$ \\
\hline
\end{tabular}

\subsection{Destilação e compostos secundários}

Ao final da primeira destilação, obteve-se teor alcoólico igual a $54^{\circ} \mathrm{GL}$, na segunda destilação, um teor alcoólico de $82^{\circ} \mathrm{GL}$, que foi, então, diluído em água potável para atingir teor alcoólico desejado. Os resultados obtidos, para a análise físico-química da vodca, são apresentados na Tabela 2.

Tabela 2 Análises físico-químicas da vodca filtrada em carvão ativado.

\begin{tabular}{lcc}
\hline Itens analisados & Amostra & Legislação \\
\hline Cobre $(\mathrm{mg} / \mathrm{L})$ & $\mathrm{ND}$ & $\leq 5$ \\
Extrato seco a $100^{\circ} \mathrm{C}(\mathrm{g} / \mathrm{L})$ & 0,092 & \\
Grau alcoólico real a $20^{\circ} \mathrm{C}(\% \mathrm{v} / \mathrm{v})$ & 39,71 & $36-54$ \\
Acidez volátil em ácido acético* & 15,29 & \\
Álcoois superiores* & 122,52 & \\
Álcool n-propílico* & 50,97 & \\
Álcool isobutílico* & 37,5 & \\
Álcool isoamílico* & 34,05 & \\
Álcool sec-butílico* & $\mathrm{ND}$ & \\
Álcool n-butílico* & $\mathrm{ND}$ & \\
Furfural* & $\mathrm{ND}$ & \\
Aldeídos em aldeído acético* & 6,02 & \\
Ésteres em acetado de etila* & 4,5 & \\
Soma dos componentes secundários* & 148,33 & $\leq 50$ \\
Álcool metílico* & 35,04 & $\leq 20$ \\
\hline
\end{tabular}

ND- Não detectado * mg/100 mL álcool anidro 


\section{CONCLUSÃO}

A adição de sacarose ao meio hidrolisado derivado da batata é necessária para aumentar o teor de açúcares no mosto, promovendo uma maior produção de etanol em relação ao meio contendo apenas o hidrolisado, maior eficiência (89\%), maior rendimento em etanol (Yp/s = 0,47 g etanol/g ART) e maior produtividade em etanol (6,05 g/L.h).

As análises físico-químicas da vodca demonstraram uma soma de compostos congêneres maior que a permitida pela legislação brasileira para vodca que é de $50 \mathrm{mg} / 100 \mathrm{~mL}$ de álcool anidro, que poderiam ser corrigidos com uso de outros tipos de carvão ativado ou alterações na destilação.

\section{REFERÊNCIAS}

BRASIL. Decreto $\mathrm{n}^{\mathbf{0}}$ 2314, de 4 de setembro de 1997. Dispõe sobre a padronização, a classificação, o registro, a inspeção, a produção e a fiscalização de bebidas. Regulamenta a Lei $\mathrm{n}^{\circ}$ 8918 de 14 de julho de 1994. Diário Oficial [da] República Federativa do Brasil, Brasília, 5 set. 1997. Seção 1, p. 19549.

CARDOSO, M. G. (Ed.). Produção de aguardente de cana. 3. ed. Lavras: UFLA, 2013. 340 p.

INSTITUTO ADOLFO LUTZ. Normas analíticas do Instituto Adolfo Lutz: métodos químicos e físicos para análise de alimentos. 4. ed. São Paulo: IMESP, 2008. v. 1, 1000 p.

LIMA, U. A. Aguardentes. In: AQUARONE, E. et al. (Coord.). Biotecnologia industrial: alimentos e bebidas produzidos por fermentação. São Paulo: E. Blücher, 2001. v. 3, 616 p.

LIMA, A. J. B. et al. Emprego do carvão ativado para remoção de cobre em cachaça. Química Nova, São Paulo, v. 29, n. 2, p. 247-250, 2006.

MILLER, G. L. Use of dinitrosalicylic acid reagent for determination of reducing sugar.

Analytical Chemistry, Washington, v. 31, n. 3, p. 426-428, Mar. 1959

SIŘÍŠŤOVÁ, L. et al. Changes in quality parameters of vodka filtered through activated charcoal. Czech Journal of Food Science, Praha, v. 30, n. 5, p. 474-482, 2012.

\section{AGRADECIMENTOS}

A FAPEMIG pelo auxílio para participação no evento, à CAPES pela bolsa de Mestrado e à empresa Romerlabs, por ceder, gentilmente, as enzimas utilizadas neste estudo. 